\section{DETECTION OF CARBON MONOXIDE PRODUCTION AS A RESULT OF THE INTERACTION OF FIVE VOLATILE ANESTHETICS AND DESICCATED SODALIME WITH AN ELECTROCHEMICAL CARBON MONOXIDE SENSOR IN AN ANESTHETIC CIRCUIT COMPARED TO GAS CHROMATOGRAPHY}

Christiaan Keijzer, $M D^{1}$, Roberto S. G. M. Perez, $P h D^{2}$ and Jaap J. de Lange, $\mathrm{MD}, \mathrm{PhD}^{2}$
From the ${ }^{1}$ Department of Anesthesiology and Intensive Care, The Netherlands Cancer Institute - Antoni van Leeuwenhoek Hospital, Plesmanlaan 121, Amsterdam, 1066 CX, The Netherlands; ${ }^{2}$ Department of Anesthesiology, VU University Medical Center, Amsterdam, The Netherlands.

Received 12 February 2007. Accepted for publication 8 June 2007.

Address correspondence to C. Keijzer, Department of Anesthesiology and Intensive Care, The Netherlands Cancer Institute Antoni van Leeuwenhoek Hospital, Plesmanlaan 121, Amsterdam, 1066 CX, The Netherlands.

E-mail: c.keijzer@nki.nl
Keijzer C, Perez RSGM, deLange JJ. Detection of carbon monoxide production as a result of the interaction of five volatile anesthetics and desiccated sodalime with an electrochemical carbon monoxide sensor in an anesthetic circuit compared to gas chromatography.

J Clin Monit Comput 2007; 21:257-264

ABSTRACT. Objectives. There is a continuing risk of production of toxic levels of carbon monoxide (CO) as a result of interaction of volatile anesthetics and desiccated strong base carbon dioxide absorbents like soda lime. The aim of this study is to establish the reliability of detection of CO levels by an electrochemical carbon monoxide sensor compared to gas chromatography. Methods. Completely desiccated sodalime was conducted through a circle anesthesia system connected to an artificial lung. For different rates of $\mathrm{CO}$ production, a low flow anesthesia with a oxygen/nitrous oxide mixture was maintained using five volatile anesthetics. For quantification of CO production, a portable gas chromatograph (GC) was connected to this setup, as well as a Bedfont EC40 electrochemical carbon monoxide sensor (ES) with a claimed reliable sensitivity of 0-200 parts per million (ppm) and a maximum detection range of more than $5500 \mathrm{ppm}$. To assess the agreement between the GC and ES measurements the intra class correlation coefficient (ICC) and the 95\% limits of agreement were calculated. Bland and Altman scatterplots were made to visualize the difference between measurements. Results. For concentrations up to $200 \mathrm{ppm}$, no significant differences between the GC and ES mean CO measurements were found in the halothane experiments. However $\mathrm{CO}$ was not accurately measured at every moment during these experiments by the ES. For concentrations above $200 \mathrm{ppm}$ the results of the two instruments differed significantly. The ES malfunctioned when exposed to sevoflurane and desiccated sodalime. Conclusions. From these data we conclude that the ES can only be used as an indicator of $\mathrm{CO}$ production. When this sensor is used with sevoflurane and desiccated sodalime it is not capable of normal operation. The use of a strong base free carbon dioxide absorbent is therefore recommended.

KEY WORDS. anesthesia, inhalation, carbon dioxide absorbent, carbon monoxide, electrochemistry, monitoring, intra-operative.

\section{INTRODUCTION}

There is a continuing risk of production of high concentrations of carbon monoxide (CO)[1-5] in an anesthetic circuit as a result of interaction between inhalation anesthetics and desiccated $\mathrm{CO}_{2}$ absorbents that contain strong bases like potassium hydroxide $(\mathrm{KOH})$ and sodium hydroxide $(\mathrm{NaOH})[6,7]$. There are $\mathrm{CO}_{2}$ absorbents available that lack these strong bases and don't produce any $\mathrm{CO}$ when desiccated $[8,9]$. However, the use of these carbon dioxide absorbents is more expensive $[7,10]$ than 
regular absorbents, therefore detecting $\mathrm{CO}$ inside the anesthesia circuit using an electrochemical could be an easier and cheaper alternative to maintain a safe patient environment, when using strong base containing $\mathrm{CO}_{2}$ absorbents. Some electrochemical CO sensors have been studied in the presence of anesthetic gases [11, 12], but only with the sensor placed in a sealed container, adding prepared $\mathrm{CO}$ gas mixtures that contained $\mathrm{CO}$ as a result of interaction between desflurane or isoflurane with a desiccated absorbent. No study has been performed with an electrochemical sensor measuring $\mathrm{CO}$ inside an anesthesia circle system

Therefore, the aim of this study is to investigate the reliability of detection of $\mathrm{CO}$ levels by an electrochemical carbon monoxide sensor compared to gas chromatography in a patient model where carbon monoxide is generated inside an anesthesia circuit, as a result of interaction between all modern inhalation anesthetics and desiccated sodalime. We wish to determine if monitoring of $\mathrm{CO}$ with this sensor can provide an early warning sign of $\mathrm{CO}$ production inside an anesthetic circuit.

\section{METHODS AND MATERIALS}

\section{Patient Model}

To simulate a patient model, we used a circle anesthesia system (Cicero EM, Dräger) connected to an artificial lung (Demonstrationsthorax, Dräger).

Three sample lines were connected to the Y-piece of the circle system: one to the infrared anesthetic vapor analyzer (SAM, Marquette) sampling at $200 \mathrm{ml} / \mathrm{min}$, one to a small lumen gas chromatography sample line connected to the gas chromatograph and one to a Datex capnograph providing a constant flow of $200 \mathrm{ml} / \mathrm{min}$ to an electrochemical carbon monoxide sensor (ES). Sampled gas from the outlet of the infrared anesthetic vapor analyzer and the capnograph was returned to the circle anesthesia system.

For the carbon monoxide production inside the circle system we used desflurane, sevoflurane, isoflurane, enflurane and halothane in combination with completely desiccated carbon dioxide absorbent Drägersorb 800 plus ${ }^{\circledR}$, to obtain different concentrations of carbon monoxide as previously published [13].

The carbon dioxide absorbent was dried completely by using an oxygen flow of $15 \mathrm{l} / \mathrm{min}$ in glass containers until no additional weight reduction could be measured. A weight reduction of $16 \%$ was established in accordance with the producers' specifications.

\section{Experiments}

For each anesthetic, an experiment was performed in which $950 \mathrm{~g}$ of dry absorbent was used. The ventilator was set in IPPV mode with a tidal volume of $600 \mathrm{ml}$, a frequency of 14 and 5 PEEP. After an equilibration with $40 \%$ oxygen and $60 \%$ nitrous oxide was established at a fresh gas flow (FGF) of $51 / \mathrm{min}$, the GC run of 36 samples was started at $t=0$. After $1 \mathrm{~min}$, anesthetic vapor was introduced by a standard vaporizer. The dial was set until the vapor analyzer showed approximately $3.0 \mathrm{vol} \%$ of desflurane, 0.8 vol $\%$ sevoflurane, 0.8 vol $\%$ isoflurane, $0.6 \mathrm{vol} \%$ enflurane or $0.45 \mathrm{vol} \%$ halothane, after which the FGF was reduced to $500 \mathrm{ml} / \mathrm{min}$. This concentration of anesthetic vapor was maintained during a 3-h experiment. No carbon dioxide was added to the anesthetic circuit. All experiments were performed in duplicate to verify the reproducibility of the $\mathrm{CO}$ measurements. For control the same experiments were performed using fresh carbon dioxide absorbent.

\section{Gas chromatography carbon monoxide measurements}

Gas was automatically sampled every $5 \mathrm{~min}$ from the anesthetic circuit at a rate of $100 \mathrm{ml} / \mathrm{min}$, during $10 \mathrm{~s}$ until $180 \mathrm{~min}$. The concentrations of carbon monoxide were measured with a portable gas chromatograph (Varian Chrompack CP 2003P) with a high sensitivity thermal conductivity detector (TCD), and a Mollsieve 5A column. The reliable measurement range of this setup is $1 \mathrm{ppm}$ to $1 \times 10^{6} \mathrm{ppm}$ with a margin of error of $10 \%$. The GC was calibrated with two calibration mixtures of 210 and 981 parts per million (ppm) CO in nitrogen (Hoekloos specialty gasses, Dieren). The calibration with $981 \mathrm{ppm}$ CO confirmed the linearity of the TCD. The GC was connected to a desktop PC for control of the GC and data recording, analysis and storage.

\section{Electrochemical carbon monoxide measurements}

Sampled gas from the capnograph was lead to a Bedfont EC40 electrochemical sensor. This electrochemical sensor has a range of 0-200 parts per million ( $\mathrm{ppm}$ ) and an accuracy of $\pm 10 \%$, the displayed concentration has a maximum value of $2,000 \mathrm{ppm}$. The sensor is also equipped with a external analog signal, which we used to record the carbon monoxide concentration per second through an analog-digital converter inside the same desktop PC, as mentioned above. The ES was calibrated with a mixture of 210 and $981 \mathrm{ppm} \mathrm{CO}$ in nitrogen (Hoekloos specialty gasses, Dieren). 


\section{Statistical Analysis}

All statistical analyses were performed with SPSS for Windows version 12.0.

Carbon monoxide measurements from the electrochemical monitor were averaged over the same time periods of approximately $5 \mathrm{~min}$ as the gas chromatograph measured for comparison.

The results from the electrochemical sensor and the gas chromatograph were compared for differences using the Mann-Whitney test. The intra class correlation coefficient (ICC) and the 95\% limits of agreement were used to assess the agreement between measurements. To visualize the size of difference between measurements and their distribution around zero, Bland and Altman scatterplots were made for all experiments [14]. For all analyses, the significance level was set at .05 .

\section{RESULTS}

The control experiments using fresh carbon dioxide absorbent revealed no carbon monoxide production measured by the ES or GC.

There were no differences in the carbon monoxide concentrations in the two consecutive measurements for each anesthetic with desiccated absorbent for the GC and ES (Mann-Whitney $U$ test: $p>0.05$ ). Therefore the average mean $\mathrm{CO}$ concentrations (GC and ES) were calculated from the two experiments of each anesthetic vapor and plotted in Figure 1 for halothane, in Figure 2 for enflurane, in Figure 3 for isoflurane and in Figure 4 for desflurane. The CO curves for the GC were previously published [13].

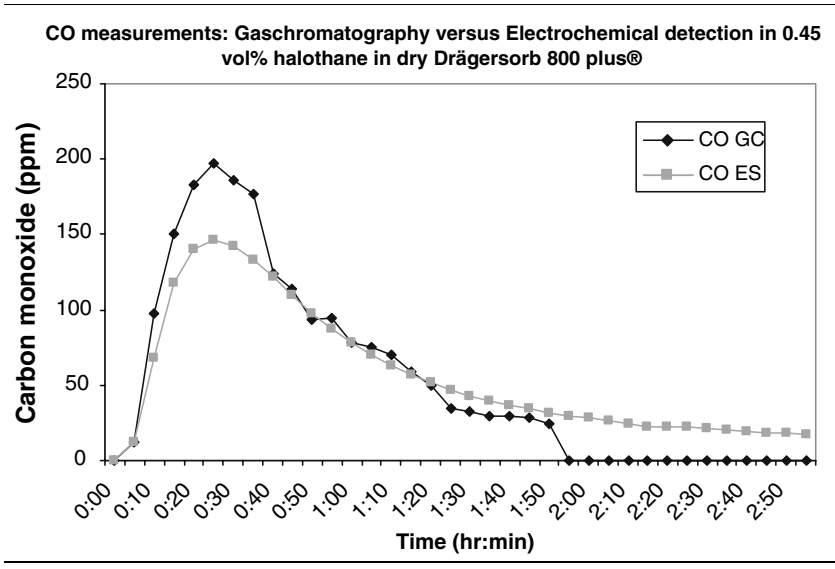

Fig. 1. Carbon monoxide (CO) measurements in parts per million (ppm) by a gaschromatograph (GC) versus an electrochemical sensor (ES). Measurements are averages of two experiments performed in a closed circle system using 0.45 vol\% halothane in completely dry Drägersorb 800 plus ${ }^{\circledR}$.

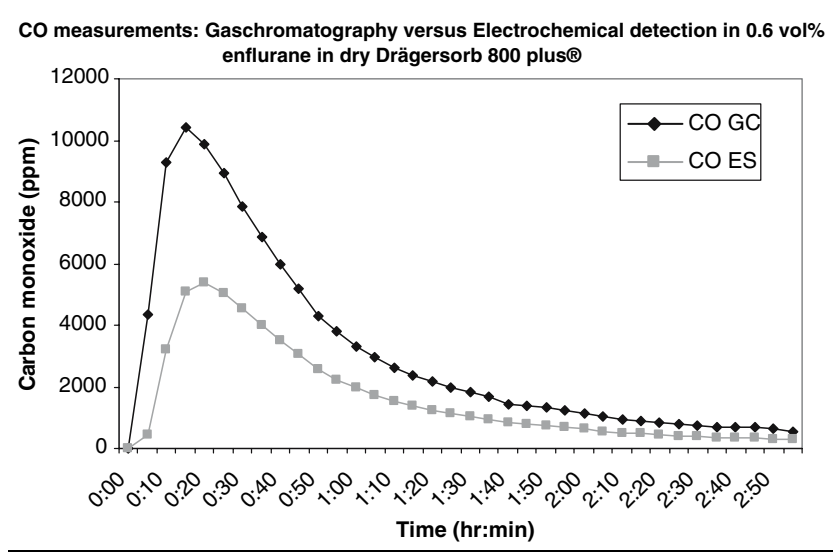

Fig. 2. Carbon monoxide (CO) measurements in parts per million (ppm) by a gaschromatograph (GC) versus an electrochemical sensor (ES). Measurements are averages of two experiments performed in a closed circle system using 0.6 vol\% enflurane in completely dry Drägersorb 800 plus ${ }^{\circledR}$.

In the Figures the two curves of the electrochemical sensor and the gas chromatograph are only comparable for the halothane experiment during the first $20 \mathrm{~min}$ and from $t=40 \mathrm{~min}$ until $t=155 \mathrm{~min}$. In the period between 20 and $40 \mathrm{~min}$ there is an underestimation of the measured CO concentration. From $t=155$ min the GC does not detect any $\mathrm{CO}$ anymore while the ES is still measuring $\mathrm{CO}$ in concentrations below $50 \mathrm{ppm}$. In the other experiments the two curves of the ES and the GC depict a clear underestimation of the measured $\mathrm{CO}$ concentrations by the ES.

In the desflurane and enflurane experiments we noted that the upper range of the electrochemical sensor through the analog output was $5667 \mathrm{ppm}$ of carbon monoxide. This explains the plateau phase in the desflurane ES-curve

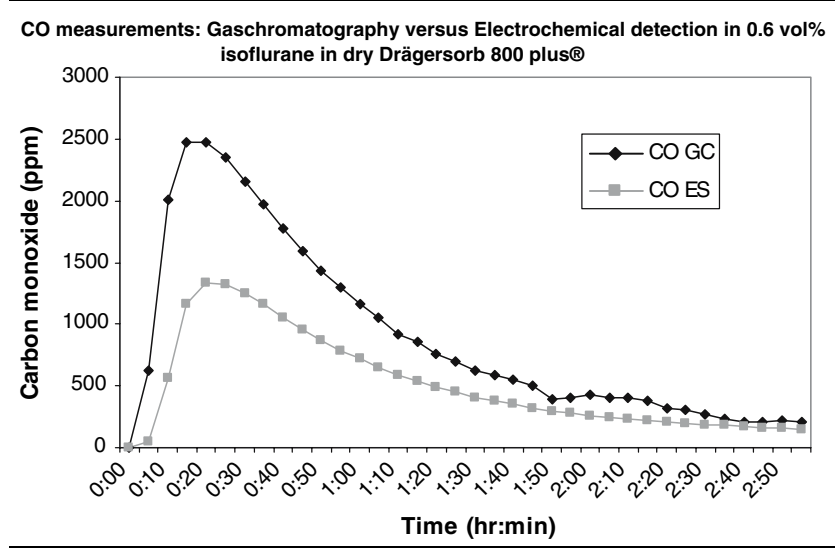

Fig. 3. Carbon monoxide (CO) measurements in parts per million (ppm) by a gaschromatograph (GC) versus an electrochemical sensor (ES). Measurements are averages of two experiments performed in a closed circle system using 0.6 vol\% isoflurane in completely dry Drägersorb 800 plus ${ }^{\circledR}$. 


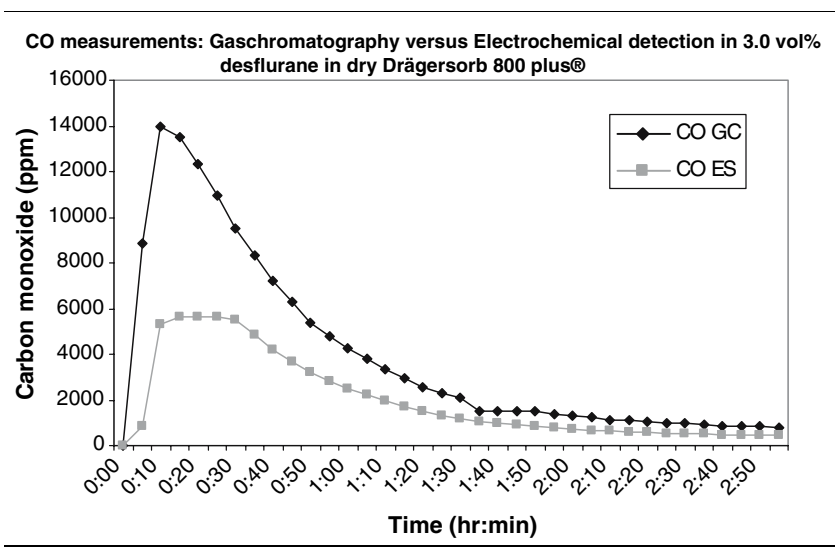

Fig. 4. Carbon monoxide (CO) measurements in parts per million (ppm) by a gaschromatograph (GC) versus an electrochemical sensor (ES). Measurements are averages of two experiments performed in a closed circle system using 3.0 vol\% desflurane in completely dry Drägersorb 800 plus ${ }^{\circledR}$.

when the GC measures peak CO-concentrations.

The sevoflurane experiments are not depicted because of unexpected behavior of the ES during the first experiment: the display showed a rapid increase in CO concentration to the upper limit of $2000 \mathrm{ppm}$ in the display and $5667 \mathrm{ppm}$ through the analog output within one hour. After that the sensor output suddenly dropped to $-2000 \mathrm{ppm}$ in the display and $-5670 \mathrm{ppm}$ through the analog output. The sensor was then disconnected from the circle system and no longer used in the sevoflurane experiments with desiccated absorbent.
After the disconnection the sensor was flushed with air which had no effect on the displayed CO concentration that kept indicating $-2000 \mathrm{ppm}$ for approximately twelve hours. Afterwards the sensor operated normally again and exposure to the calibration mixtures of $\mathrm{CO}$ in nitrogen resulted in the corresponding $\mathrm{CO}$ concentrations.

In Table 1 all calculated data are presented. Mean carbon monoxide concentrations in the halothane experiments correspond with a GC/ES fraction of 0.931.00. No significant differences were found for the halothane experiments between the GC and ES data, and the high ICC between both assessments is good. The other experiments demonstrate significant differences between GC and ES data and moderate ICC's, with a GC/ES fraction of 1.73 to 2.05 . The $95 \%$ limits of agreements show that the difference between the GC and ES is maximally $100 \mathrm{ppm}$ for the halothane experiments, with a discrepancy being equally likely in both directions. For the isoflurane and desflurane experiments, the difference between both instruments maximally differs respectively 1560 and 9825 ppm, whereby the ES measurements tend to underestimate the amount of $\mathrm{CO}$ produced. The Bland and Altman scatter plots (Fig. 512) also depict the distribution of the differences around zero between experiments, and also show a relationship between the amount of $\mathrm{CO}$ production and the size of the observed difference between both instruments for all experiments.

Table 1. Carbon monoxide (CO) measurements in parts per million (ppm) by a gaschromatograph (GC) versus an electrochemical sensor (ES).

\begin{tabular}{|c|c|c|c|c|c|c|}
\hline Experiment & Mean $[\mathrm{CO}]$ from $\mathrm{GC}$ & Mean [CO] from ES & $\mathrm{GC} / \mathrm{ES}$ & $p$ & $\mathrm{ICC}$ & $95 \%$ limits \\
\hline H 1 & $51 \pm 10$ & $51 \pm 7$ & 1.00 & 0.303 & 0.91 & $-43.8-43.8$ \\
\hline E 1 & $2914 \pm 493$ & $1473 \pm 250$ & 1.98 & 0.005 & 0.79 & $-1715.8-4599.0$ \\
\hline E 2 & $3240 \pm 510$ & $1760 \pm 276$ & 1.84 & 0.015 & 0.81 & $-1626.4-4587.1$ \\
\hline I 1 & $902 \pm 126$ & $520 \pm 67$ & 1.73 & 0.018 & 0.62 & $-397.1-1160.5$ \\
\hline D 1 & $3902 \pm 660$ & $1967 \pm 307$ & 2.05 & 0.047 & 0.59 & $-2783.1-6653.3$ \\
\hline D 2 & $4069 \pm 677$ & $1986 \pm 310$ & 1.98 & 0.004 & 0.57 & $-2899.4-6917.4$ \\
\hline S 1 & $23 \pm 6$ & $\mathrm{~N} / \mathrm{A}$ & - & - & - & - \\
\hline S 2 & $27 \pm 7$ & $\mathrm{~N} / \mathrm{A}$ & - & - & - & - \\
\hline
\end{tabular}

Legend: column 1 names the two experiments for each desiccated absorbent: $\mathrm{H}=$ halothane, $\mathrm{I}=$ isoflurane, $\mathrm{E}=$ enflurane, $\mathrm{D}=$ desflurane, $\mathrm{S}=$ sevoflurane. Column 2 displays the mean $\mathrm{CO}$ concentration $\pm \mathrm{SE}$ measured by the GC. Column 3 displays the mean CO concentration \pm SE measured by the electrochemical sensor. The ES values are not depicted for the sevoflurane experiments because of the malfunctioning of the ES in these experiments (described in the results and discussion). Only for the halothane experiments these mean concentrations correlate between the GC and ES. For all other experiments (except sevoflurane) there is a large underestimation of the CO measured by the ES compared to the GC. Column 4 displays the fraction columns 3 and 4 . Column 5 displays the $p$ value of the MannWhitney test comparing the results from the GC and the ES. Column 6 displays the intra class correlation value (ICC) that is calculated from a univariate analysis of variance between the results from the GC and the ES. The last column shows the $95 \%$ limits of agreement of the comparison between the GC and ES Here a wide range of differences between GC and ES is demonstrated. 


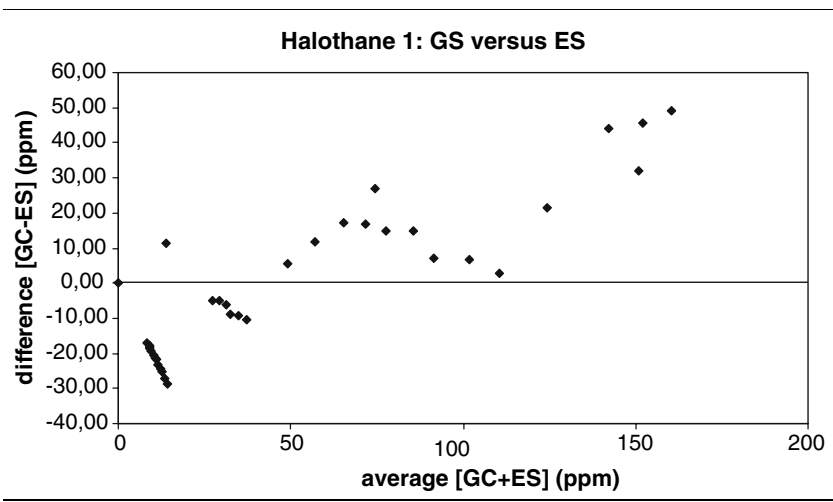

Fig. 5. Scatterplot of difference between CO concentrations of the GC and $E S$ measurements against the mean concentrations of $G C$ and $E S$ in the first halothane experiment. Concentrations in parts per million (ppm).

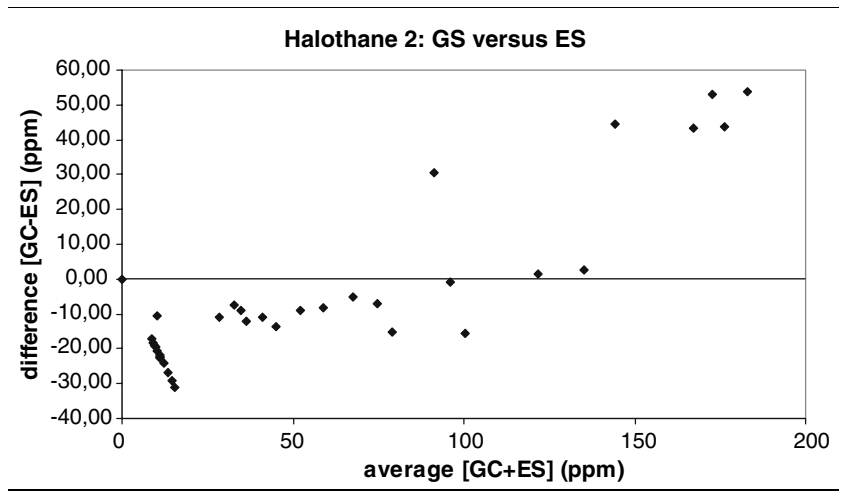

Fig. 6. Scatterplot of difference between CO concentrations of the GC and ES measurements against the mean concentrations of GC and ES in the second halothane experiment. Concentrations in parts per million (ppm).

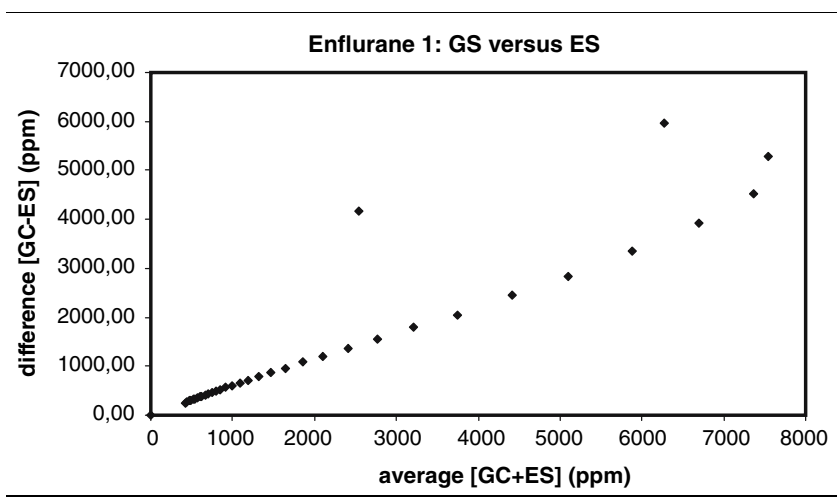

Fig. 7. Scatterplot of difference between CO concentrations of the GC and ES measurements against the mean concentrations of GC and ES in the first enflurane experiment. Concentrations in parts per million (ppm).

\section{DISCUSSION}

Previous studies [11, 12] demonstrated accurate reliability of different brands of electrochemical sensors with carbon

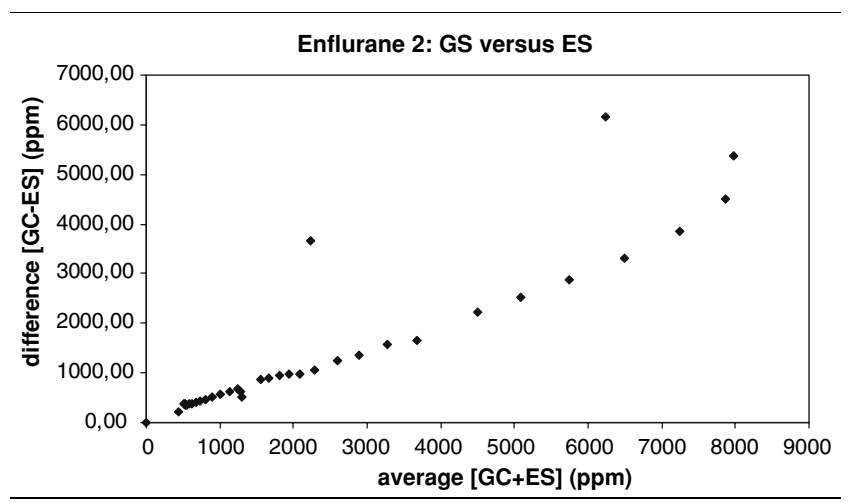

Fig. 8. Scatterplot of difference between CO concentrations of the GC and ES measurements against the mean concentrations of GC and ES in the second enflurane experiment. Concentrations in parts per million (ppm).

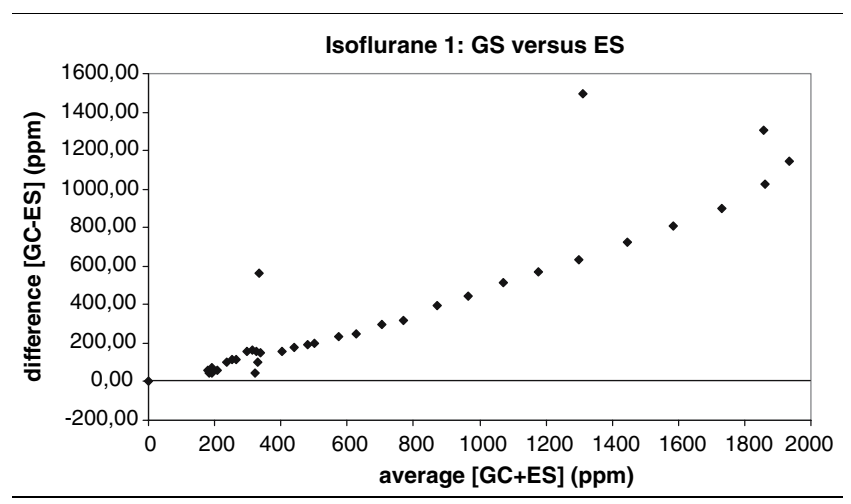

Fig. 9. Scatterplot of difference between CO concentrations of the GC and ES measurements against the mean concentrations of GC and ES in the first isoflurane experiment. Concentrations in parts per million (ppm).

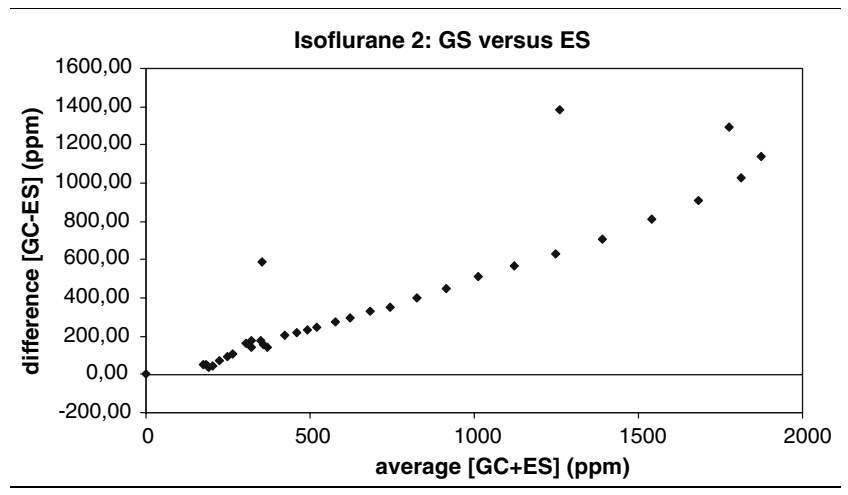

Fig. 10. Scatterplot of difference between CO concentrations of the GC and ES measurements against the mean concentrations of GC and ES in the second isoflurane experiment. Concentrations in parts per million (ppm)

monoxide production from isoflurane or desflurane and desiccated carbon dioxide absorbents within the specified range of the sensors. In this study we demonstrated that this electrochemical sensor measures comparable to a GC within the specified range regarding the total mean $\mathrm{CO}$ 


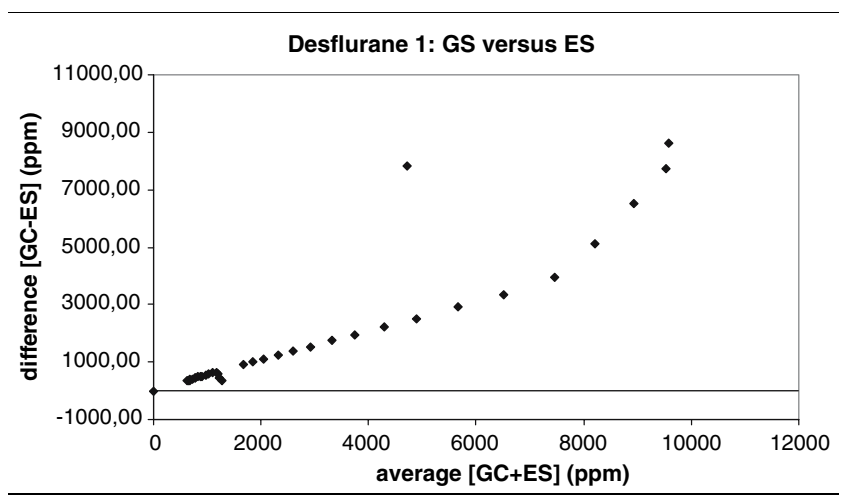

Fig. 11. Scatterplot of difference between CO concentrations of the GC and ES measurements against the mean concentrations of GC and ES in the first desflurane experiment. Concentrations in parts per million (ppm).

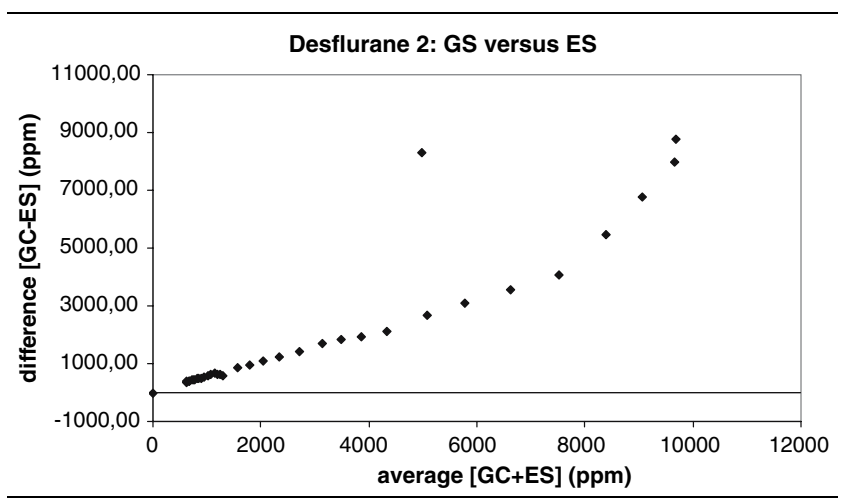

Fig. 12. Scatterplot of difference between CO concentrations of the GC and ES measurements against the mean concentrations of GC and ES in the second desflurane experiment. Concentrations in parts per million (ppm).

concentrations in the halothane experiments, but $\mathrm{CO}$ concentrations are not accurately measured by the ES on every moment during these experiments. During the halothane experiments, where concentrations of produced CO were below $200 \mathrm{ppm}$., the ES underestimated the $\mathrm{CO}$ concentrations measured compared to the GC. At the end of this experiment the ES still measured low concentrations of $\mathrm{CO}$, while the $\mathrm{GC}$ did not detect any $\mathrm{CO}$ at that time. A possible explanation for this phenomenon is that the ES is a sensor where gas has to diffuse through, while the GC measures from gas samples. This diffusion process within the ES combined with the low flow setting of the experiments probably keeps low concentrations of $\mathrm{CO}$ inside the ES while the $\mathrm{CO}$ formation process is terminated.

There is no relation between the CO concentrations measured by the GC compared to the ES for the experiments with sevoflurane in combination with desiccated sodalime. Here the sensor displayed negative concentra- tions of CO while the actual (GC) carbon monoxide concentrations were within the specified range of the sensor. In these experiments we also noticed a high degree of sevoflurane degradation because of the discrepancy between the dial setting of the vaporizer and the measured sevoflurane concentrations in the circle system as previously reported [13]. When sevoflurane degradation occurs in the presence of this sensor, the display will show increasing concentrations of $\mathrm{CO}$ before it shuts down and is therefore providing a warning signal of sevoflurane degradation as result of absorbent desiccation, but not of CO production. Funk et al. [15] demonstrated that when sevoflurane degrades in desiccated sodalime, also compound $\mathrm{A}$ to $\mathrm{E}$, methanol, formaldehyde, fluoride and formic acid are produced. From the producer of the electrochemical sensor we know that the reaction mechanism of the sensing electrode (represented by the equation: $\mathrm{CO}+\mathrm{H}_{2} \mathrm{O}=\mathrm{CO}_{2}+2 \mathrm{H}^{+}+2 \mathrm{e}^{-}$) can easily be disturbed in the presence of formaldehyde, formic acid or methanol. Because this sensor also contains an inboard filter to remove acid gases and alcohols we assume that the produced formaldehyde is responsible for the inaccuracy of the sensor in this experiment. Because of these toxic byproducts of sevoflurane degradation we prefer the use of a carbon dioxide absorbent that does not degrade sevoflurane when desiccated.

Outside the specified range of this ES, the measured $\mathrm{CO}$ concentration are below the actual values measured by the GC for the other experiments. This applies to the experiments with enflurane, isoflurane and desflurane in combination with desiccated sodalime.

This sensor may provide an early warning signal of $\mathrm{CO}$ production, however, with a highly underestimated concentration displayed. For example: in the experiments with desflurane the GC measured in the first sample after 5 min CO concentrations of approximately $9000 \mathrm{ppm}$. The ES however, started to measure concentrations of $100 \mathrm{ppm}$ after $2 \mathrm{~min}$, that rapidly increased to $700 \mathrm{ppm}$ after $3 \mathrm{~min}$ and $800 \mathrm{ppm}$ after $5 \mathrm{~min}$ which is about 10\% of the measured concentration by the GC. However, this comparison can only be made for $T=5 \mathrm{~min}$ when the $\mathrm{GC}$ returns its first sample result. To accurately determine the agreement between the ES and GC results at earlier measurement moments, a higher GC sampling frequency should be used. This is not possible for the GC in the present study because at least 4 min analysis time is required with this GC. Hypothesizing that the earlier ES results are also approximately $10 \%$ of the actual CO concentrations, the alarm of the ES could be set at $100 \mathrm{ppm}$ which would correspond to $1000 \mathrm{ppm}$ of CO. At this alarm level, this sensor would have given a warning signal of CO production after $2 \mathrm{~min}$ in the present study. The alarm on the ES can be accurately set at every ppm 
level wanted, above this level a very loud beep is produced until the concentration of $\mathrm{CO}$ is below this level. Regarding the toxicity of $\mathrm{CO}$, the Henderson and Haggard's Index of Toxic effect [16] indicates that one hour of exposure of more than $1500 \mathrm{ppm}$ of $\mathrm{CO}$ is dangerous to life. Therefore the patient would not be in danger when exposed to these $\mathrm{CO}$ concentrations in this short time period, under the condition that the absorbent would be changed immediately after the first warning of $\mathrm{CO}$ production. We therefore conclude that this ES can be possibly used as an indicator of $\mathrm{CO}$ production in an anesthetic circuit under the condition that immediate action is undertaken on the first sign of $\mathrm{CO}$ production when using a 'classic' strong base containing absorbent.

With respect to the cost benefit of using an electrochemical CO sensor, we calculated the extra cost using the strong base free Drägersorb free ${ }^{\circledR}$ for the last 2 years instead of Drägersorb 800 plus ${ }^{\circledR}$ for the Netherlands cancer institute - Antoni van Leeuwenhoek hospital at approximately $€ 2200,-$ per year for five operating theatres. These extra costs result from the higher pricing of the strong base free absorbent and the lower carbon dioxide absorbent capacity of these type of absorbents. A Bedfont electrochemical sensor device costs approximately $€ 1000$,- with an electrochemical sensor cell lifetime of 3 years. A replacement cell costs approximately $€ 300,-$. The extra costs of the strong base free absorbent during a period of 3 years would amount to $€ 6600$,- while the purchase of five electrochemical sensor devices would cost $€ 5000,-$. The 3 years thereafter the extra costs of the strong base free absorbents would be still $€ 6600,-$ while the purchase of five replacement electrochemical sensors would cost $€ 1500,-$. Based on these figures the relative cost reduction per operating theatre would be approximately $€ 300$,- yearly for the first 3 years and about $€ 1300$,- for the following years when using this electrochemical sensor in stead of replacing the absorbent to a strong base free type. However, considering the inaccuracy of the ES and the possible toxic byproducts of sevoflurane degradation we prefer the use of a safe strong base free absorbent in stead of an electrochemical CO sensor.

\section{CONCLUSION}

From this study we conclude that this electrochemical sensor may provide an early but inaccurate warning sign of $\mathrm{CO}$ production when using a strong base containing carbon dioxide absorbent and vapor anesthetics in an anesthesia circle system. When sevoflurane is degraded in desiccated sodalime, this sensor is not capable of normal operation and will display high (incorrect) concentrations of $\mathrm{CO}$ within half an hour.

Using this electrochemical sensor instead of replacing the strong base containing absorbent to a strong base free type will lead to a slight cost reduction over three to 6 years. However, we recommend the use of a strong base free absorbent, in stead of an electrochemical CO sensor, based on the inaccuracy of this sensor and the possible toxic byproducts of sevoflurane degradation.

\section{REFERENCES}

1. Moon R, Meyer A, Scott D, Fox E, Millington D, Norwood D. Intraoperative carbon monoxide toxicity. Anesthesiology 1990; 73: A1089.

2. Moon R, Ingram C, Brunner E, Meyer A. Spontaneous generation of carbon monoxide within anesthetic circuits. Anesthesiology 1991; 75: A873.

3. Lentz R. CO poisoning during anesthesia poses puzzles. APSF Newsletter 1994; 9: 13-14.

4. Berry PD, Sessler DI, Larson MD. Severe carbon monoxide poisoning during desflurane anesthesia. Anesthesiology 1999; 90: 613-616.

5. Fatheree RA, Leighton BL. Acute respiratory distress syndrome after an exothermic baralyme-sevoflurane reaction. Anesthesiology 2004; 101: 531-533.

6. Neumann MA, Laster MJ, Weiskopf RB, et al. The elimination of sodium and potassium hydroxides from desiccated soda lime diminishes degradation of desflurane to carbon monoxide and sevoflurane to compound A but does not compromise carbon dioxide absorption. Anesth Analg 1999; 89: 768-773.

7. Stabernack CR, Brown R, Laster MJ, Dudziak R, Eger EI. Absorbents differ enormously in their capacity to produce compound A and carbon monoxide. Anesth Analg 2000; 90: 1428-1435.

8. Murray JM, Renfrew CW, Bedi A, McCrystal CB, Jones DS, Fee JP. Amsorb: a new carbon dioxide absorbent for use in anesthetic breathing systems. Anesthesiology 1999; 91: 13421348.

9. Struys MM, Bouche MP, Rolly G, et al. Production of compound $\mathrm{A}$ and carbon monoxide in circle systems: an in vitro comparison of two carbon dioxide absorbents. Anaesthesia 2004; 59: 584-589.

10. Higuchi H, Adachi Y, Arimura S, Kanno M, Satoh T. The carbon dioxide absorption capacity of Amsorb is half that of soda lime. Anesth Analg 2001; 93: 221-225.

11. Dunning M III, Woehlck HJ. Performance of an electrochemical carbon monoxide monitor in the presence of anesthetic gases. J Clin Monit 1997; 13: 357-362.

12. Bermudez JA. Investigation of electrochemical carbon monoxide sensor monitoring of anesthetic gas mixtures. Anesthesiology 2003; 99: 1233-1235.

13. Keijzer C, Perez RS, de Lange JJ. Carbon monoxide production from five volatile anesthetics in dry sodalime in a patient model: halothane and sevoflurane do produce carbon monoxide; temperature is a poor predictor of carbon monoxide production. BMC Anesthesiol 2005; 5: 6. 
14. Altman D. Practical statistics for medical research. Chapman \& Hall, 1999.

15. Funk W, Gruber M, Wild K, Hobbhahn J. Dry soda lime markedly degrades sevoflurane during simulated inhalation induction. Br J Anaesth 1999; 82: 193-198.
16. Altman C. AANA journal course: update for nurse anesthetists-carbon monoxide poisoning: role of the anesthesia machine's carbon dioxide absorption system. AANA J 1996; 64: 41-47. 